\title{
A Detailed Analysis Of Clinical Measurement Error In Ultrafiltration In Peritoneal Dialysis
}

\section{Zanzhe Yu}

Renji Hospital

Zhuqing Wang

Renji Hospital

Qin Wang

Renji Hospital

Minfang Zhang

Renji Hospital

Haijiao Jin

Renji Hospital

Li Ding

Renji Hospital

Hao Yan

Renji Hospital

Jiaying Huang

Renji Hospital

Yan Jin

Renji Hospital

Simon Davies

Keele University

Wei Fang

Renji Hospital

Zhaohui Ni ( $\sim$ profnizh@126.com )

Renji Hospital

\section{Research Article}

Keywords: dialysate drainage, ultrafiltration, humidity, gravity

Posted Date: June 21st, 2021

DOI: https://doi.org/10.21203/rs.3.rs-574330/v1 
License: (c) (i) This work is licensed under a Creative Commons Attribution 4.0 International License. Read Full License 


\section{Abstract}

\section{Background}

It has been noticed for years that ultrafiltration is important for survival in peritoneal dialysis. On the other hand, ultrafiltration measurement is much more complicated than it thought to be. Both overfill and flush before fill used to be source of measurement error. However, controversy finding around ultrafiltration in peritoneal dialysis still exists.

\section{Methods}

Four different brands of dialysate were purchased from the market. The freshest dialysate available in the market were intentionally picked. The dialysate were all 2L, 2.5\% dextrose and traditional lactate buffered PD solution. They were stored in four different conditions with controlled temperature and humidity. The bags were weight at baseline, 6 months and 12 months of storage. Specific gravity was measured in mixed 24 hour drainage dialysate from 261 CAPD patients in a cross sectional manner.

Results

There was significant difference in dialysate bag weight at baseline between brands. The weight declined significantly after 12 months storage. The weight loss was more significant in higher temperature and lower humidity. The dialysate in non-PVC package lose less weight than PVC package. The specific gravity of dialysate drainage was significantly higher than pure water and related to dialysate protein concentration.

\section{Conclusion}

Storage condition and duration, as well as the type of the dialysate package gave extra variance in overfill volume. The fact that specific gravity of dialysate drainage is higher than $1 \mathrm{~g} / \mathrm{ml}$ also contributes to systemic measurement error of ultrafiltration in manual exchanges.

Trial Registration: ClinicalTrials.gov ID: NCT03864120 (March 8, 2019) (Understand the Difference Between Clinical Measured Ultrafiltration and Real Ultrafiltration)

\section{Background}

It has been noticed for years that ultrafiltration is important for survival in peritoneal dialysis. It has been part of the guideline target. ${ }^{1-3}$ It is also an important parameter of peritoneal membrane function. Incorrect ultrafiltration measurement may mislead the diagnosis of ultrafiltration failure. ${ }^{4}$ On the other hand, it has been noticed that ultrafiltration measurement is much more complicated than it thought to be. ${ }^{4-6}$ Both overfill and flush before fill used to be source of measurement error. The practice way of measure ultrafiltration in CAPD patients was suggested to weight "whole" drain bag and subtract an appropriate overfill volume. ${ }^{6}$ 
However, controversy finding around ultrafiltration in peritoneal dialysis still exists. The UF difference between APD and CAPD is difficult to understand. It is widely accepted that CAPD is as good as APD in terms of preserving residual renal function, if not better. Meanwhile, a favoured 24 hour UF in CAPD has been noticed in several studies. ${ }^{7-10}$ Neglecting overfill used to be a reason for over estimating UF in CAPD. However, there were studies which had clearly accounted for overfill still found a favored UF in CAPD compared to APD. ${ }^{10}$ The best ultrafiltration cutoff and related daily sodium removal are rather different between studies. Even guidelines gave different target too. More recently, ISPD guideline decide not to give any numeric target of ultrafiltration but emphasis the importance of ultrafiltration for patient survival. ${ }^{11}$

The current study is to give a detailed analysis of clinical measurement error in ultrafiltration in peritoneal dialysis.

The study adheres to CONSORT 2010 reporting guideline.

\section{Methods}

Study design and material

Four different brands of dialysate were purchased from the market. The dialysate were all $2 \mathrm{~L}, 2.5 \%$ dextrose and traditional lactate buffered PD solution. Brand $A$ and $B$ were in PVC package. Brand $C$ and $D$ were in non-PVC package. (Appendix Table 1) The freshest dialysate available in the market were intentionally picked. The time duration between manufacture data to baseline measurement were from 43 to 105 days.

At baseline, the bags were weight as whole package. The outer package of 4 bags of each brands were removed and weighted separately. The other bags were then stored in four different conditions with controlled temperature and humidity. The whole bags were weight at baseline, 6 months and 12 months of storage. The detailed temperature and humidity condition was shown as following.

Condition $1,5^{\circ} \mathrm{C}$ and uncontrolled humidity. $\mathrm{N}=5$ for each brand

Condition $2,25^{\circ} \mathrm{C}$ and $40 \%$ humidity. $\mathrm{N}=4$ for each brand

Condition $3,30^{\circ} \mathrm{C}$ and $30 \%$ humidity. $\mathrm{N}=4$ for each brand

Condition $4,40^{\circ} \mathrm{C}$ and $20 \%$ humidity. $\mathrm{N}=5$ for each brand

Sample size calculation

According to preliminary measurement, a $2 \mathrm{~L}$ dialysate bag is weight around $2200 \pm 5 \mathrm{~g} . \mathrm{n}=4$ is big enough to pick $10 \mathrm{~g}$ difference between different brands. (type I error, 0.05 and power $=0.8$ ) $\mathrm{N}=5$ is big enough to pick a $12 \mathrm{~g}(\mathrm{SD}=5)$ change in weight before and after storage. $\mathrm{N}=3$ is enough to pick a $20 \mathrm{~g}$ 
$(S D=5)$ change in weight before and after storage. 5 bags of brand $A, B$ and $D$ were stored in each of the 4 conditions. For brand $\mathrm{C}, 4$ bags were stored in condition 1 and 4 , and 3 bags were stored in condition 2and 3.

261 CAPD patients follow up in our center were enrolled in the study. They were going through their routine dialysis adequacy test. Specific gravity of the drainage dialysate was measured by weighting $1 \mathrm{ml}$ of the mixed 24 hour drainage dialysate, the same sample as their dialysis adequacy test. Specific gravity of pure water was also measured by same method as control. Dialysate sodium, potassium, protein and glucose were also measured as part of their routine test.

Statistical analysis

One way ANOVA was used to measure the difference between different brands. General linear model were used for repeated measurement of dialysate weight. One sample $t$ test was used to clarify the difference between dialysate specific gravity and water. The correlation between specific gravity and other parameter were identified by Pearson correlation. IBM SPSS statistics 20 was the software used for the study.

\section{Results}

$2 \mathrm{~L}$ dialysate bag of different brand weight different at baseline

There was significant difference in weight between the four different brands. The weight was from 2222 $\pm 1.9 \mathrm{~g}$ to $2261 \pm 3.7 \mathrm{~g}$ for the whole $2 \mathrm{~L}$ bag with outer package. $(P<0.01)$ The outer package itself was different in weight too. It was between $19.1 \pm 0.4 \mathrm{~g}$ to $21.6 \pm 0.3 \mathrm{~g}$. $(P<0.01)$ But the big weight difference of whole dialysate bag could not be explained by the weight difference in outer package. (Table 1)

Table 1

Dialysate weight at baseline in different brand

\begin{tabular}{|llll|}
\hline & whole bag & outer package & bag without outer package \\
\hline$A(n=4)$ & $2250 \pm 3.6$ & $19.7 \pm 0.1$ & $2230.3 \pm 3.5$ \\
\hline$B(n=4)$ & $2221.9 \pm 1.9$ & $21.6 \pm 0.3$ & $2200.3 \pm 1.8$ \\
\hline$C(n=4)$ & $2261.2 \pm 3.7$ & $20.4 \pm 0.2$ & $2240.8 \pm 3.6$ \\
\hline$D(n=4)$ & $2229.8 \pm 2.1$ & $19.1 \pm 0.4$ & $2210.7 \pm 2.1$ \\
\hline$P$ value & $<0.01$ & $<0.01$ & $<0.01$ \\
\hline
\end{tabular}

Dialysate bag lost weight over 12 months of storage

Over the 12 months of storage, all dialysate bags lost weight. The dialysate bags lost more weight for 12 months storage time compared with 6 months. $(P<0.01$, Table 2$)$ The higher temperature and lower humidity storage condition was related to more significant weight loss. (Table 2 ) 
Table 2

Dialysate weight at baseline, 6 months and 12 months in different conditions

\begin{tabular}{|lllll|}
\hline & baseline & 6 months & 12 months & P value \\
\hline condition 1 $(n=19)$ & $2238.9 \pm 16.5$ & $2238.6 \pm 16.5$ & $2238.3 \pm 16.6$ & $<0.01$ \\
\hline condition 2 $(n=18)$ & $2238.6 \pm 14.9$ & $2230.2 \pm 15.2$ & $2224.8 \pm 15.8$ & $<0.01$ \\
\hline condition 3 $(n=18)$ & $2239.1 \pm 13.7$ & $2225.6 \pm 14.2$ & $2217.2 \pm 15.3$ & $<0.01$ \\
\hline condition 4 $(n=19)$ & $2240 \pm 16$ & $2202.9 \pm 21.3$ & $2178.3 \pm 26.7$ & $<0.01$ \\
\hline
\end{tabular}

Dialysate with PVC package lost more weight than non-PVC package

The weight loss for each brand over 12 months storage was shown in Fig. 1 and appendix Table 2. The weight of dialysate bag at 12 months depended on baseline weight, storage condition and package type (PVC or non-PVC). PVC package was related to more significant weight loss over 12 month's storage.

(Table 3)

Table 3

generalized linear model of dialysate weight at 12 months of storage

\begin{tabular}{|llll|}
\hline \multicolumn{4}{|c|}{ Multivariate } \\
\hline & Coeff. & $95 \%$ Cl & P \\
\hline baseline weight & .871 & $0.75,0.99$ & $<0.01$ \\
\hline condition 1 & 60.975 & $56.21,65.74$ & $<0.01$ \\
\hline condition 2 & 48.131 & $43.3,52.97$ & $<0.01$ \\
\hline condition 3 & 39.756 & $34.85,44.66$ & $<0.01$ \\
\hline condition 4(ref) & 0 & & \\
\hline non-PVC & 16.296 & $12.69,19.91$ & $<0.01$ \\
\hline PVC(ref) & 0 & & \\
\hline
\end{tabular}

The specific gravity of dialysate drainage was significantly higher than water and related to dialysate protein concentration

The specific gravity of dialysate drainage was $1.0136 \pm 0.009 \mathrm{~g} / \mathrm{l}$, which was significantly different to water. $(n=261, P<0.01)$ All patients enrolled were on manual exchange and on traditional lactate buffered dextrose solution. The correlation between specific gravity and protein concentration was significant. $(r=0.139, P=0.024)$ (Table 4) 
Table 4

correlation between specific gravity and other solute concentration

\begin{tabular}{|c|c|c|c|c|c|c|}
\hline & specific gravity & potassium & sodium & chlorine & glucose & protein \\
\hline specific gravity & 1 & .064 & .113 & -.037 & -.011 & $.139 *$ \\
\hline potassium & .064 & 1 & $.157 \star$ & $.261^{\star \star}$ & $-.344^{\star \star}$ & .254 *夫 \\
\hline sodium & .113 & $.157^{\star}$ & 1 & $.680 * \star$ & $-.328 * \star$ & $.270 \star \star$ \\
\hline chlorine & -.037 & $.261^{\star \star}$ & $.680 * *$ & 1 & $-.450 * *$ & $.346^{\star \star}$ \\
\hline glucose & -.011 & $-.344 * \star$ & $-.328 * \star$ & $-.450 \star \star$ & 1 & $-.368 * \star$ \\
\hline protein & $.139 *$ & $.254 \star \star$ & $.270^{\star \star *}$ & $.346 * *$ & $-.368^{\star \star}$ & 1 \\
\hline
\end{tabular}

* $P<0.05, * * P<0.01$

\section{Discussion}

Ultrafiltration is clearly important for patient survival in peritoneal dialysis. It is also an important parameter for peritoneal membrane function. It was thought to be the easiest variable to measure. Not until post 2000, we started to recognize overfill and flush before fill cause significant measurement error for ultrafiltration. ${ }^{4-6}$ The current daily practice is to weight the "whole" drain bag and minus the overfill volume. Some carefully designed clinical trials measured dialysate bags before and after. However, the controversy finding around ultrafiltration still exists to some degree. In the current study, we clarified several potential measurement errors for ultrafiltration.

Overfill exists in all brands, but different in each brand

We knew overfill exists in all brands. But how big the difference is was not clear to the public.

Theoretically, overfill should be different between brand, type and even batch. We picked the 2L, lactate buffered, $2.5 \%$ dextrose dialysate from four different brands. It was just to get a rough idea of how big the difference was. Ideally, the manufacturer should be encouraged to publish regular audits of overfill for each type of dialysate.

Storage condition does make difference for long storage duration

According most dialysate storage instruction, lower than 0 degree should be avoided. The expiration date is 24 months. From the current study, it was clear the storage duration and condition did make difference in dialysate volume. In practices, we definitely suggest dialysate should not put in incubator for long time, which would cause significant evaporation. It could also be a problem in clinical trials. Because dialysate supplement in clinical trials may not be as frequent as routine clinical use. This problem could be more significant in the investigation arm than the control arm, which may give systemic error when comparing ultrafiltration. For clinical trials, weight dialysate bags before and after is strongly suggested. The fact 
that temperature and humidity had effect on dialysate volume may also contribute to the center effect of ultrafiltration and sodium removal.

PVC and non PVC package show difference in evaporation

We also noticed the different character in evaporation between PVC and non PVC package. So far, there is no clinical data on ultrafiltration comparing PVC and non PVC package. An ongoing clinical trial from China may give us some useful information. ${ }^{12}$ The problem of storage duration and difference in evaporation character should be carefully treated.

Neglecting the effect of specific gravity leading to overestimate of ultrafiltration in CAPD

It is not surprise that the specific gravity of dialysate is slightly higher than pure water. However, it is supposed to be neglectable by almost the whole PD society. Ultrafiltration in manual exchange is measured by weight and transform to volume by divided by $1 \mathrm{~g} / \mathrm{ml}$ (specific gravity of pure water). While in APD, ultrafiltration is directly measured by machine in volume. Taking the average specific gravity from our dextrose only cohort; the potential over estimation of UF in CAPD with 8L prescribe input volume and $1 \mathrm{~L}$ UF was calculated as following.

Reported UF (L, misleading by $\mathrm{kg})$

$=[8 \mathrm{~L}$ (input volume) $+1 \mathrm{~L}(\mathrm{UF})] * 1.0136(\mathrm{~g} / \mathrm{ml})-8 \mathrm{~L}$ (input volume)

$=1.122(\mathrm{~L}$, misleading by $\mathrm{kg}$ ) (over estimate for $0.122 \mathrm{~L}$ )

For icodextrin, the specific gravity is even higher than dextrose solution. As we don't have icodextrin in Shanghai, Prof Simon Davies kindly shared the information with us. From three long dwell icodextrin dialysate samples in Stoke on Trent, the mean specific gravity was $1.026 \pm 0.006 \mathrm{~g} / \mathrm{ml}$. In another word, the potential over estimation of UF in CAPD in a single icodextrin dwell (2L) with $0.4 \mathrm{~L}$ UF was calculated as following.

Reported UF (L, misleading by $\mathrm{kg})$

$=[2 \mathrm{~L}$ (input volume) $+0.4 \mathrm{~L}(\mathrm{UF})] * 1.026(\mathrm{~g} / \mathrm{ml})-2 \mathrm{~L}$ (input volume)

$=0.461(\mathrm{~L}$, misleading by $\mathrm{kg}$ ) (over estimate for $0.061 \mathrm{~L}$ )

The gap between weight and volume is big enough to give systemic error when comparing ultrafiltration between CAPD and APD. However, measuring dialysate volume manually is not feasible. It may cause even bigger measurement error and also increase the risk of contamination. Weight instead of volume measurement is still a reasonably way for daily practice. Mobile volume measuring tool may help with this problem in clinical trial scenario. 
Limitation: In the current study, we got the dialysate bags from market. We had tried our best to get the freshest dialysate available in the market for the study. The time between manufactory to baseline measurement was still slightly different between brands (from 43 to 105 days). On the other hand, theoretically, overfill should be different between brand, type and even batch. It may give some bias when comparing between brands. However, the study was design to clarify the difference itself rather than report the exact figure of the difference.

There is argument that in real life dialysate is not likely to store in that extreme conditions as in the current study. The study was simply to clarify the fact that storage condition (temperature and humidity) and duration would make difference on dialysate weight rather than working out an exact figure of how big the difference is.

\section{Conclusions}

In conclusion, ultrafiltration measurement in peritoneal dialysis is much more complicated than we thought. Overfill and flush before fill has been noticed for some time. Storage condition and duration, as well as the type of the dialysate package also give variance in overfill volume. The fact that specific gravity of dialysate drainage is higher than $1 \mathrm{~g} / \mathrm{ml}$ also contributes to systemic measurement error of ultrafiltration in manual exchanges.

\section{Declarations}

Ethics approval and consent to participate: The study has get the ethics approval by Shanghai Jiaotong University School of medicine, Renji Hospital Ethics Committee (2018)078. Written informed consent were get from each participate.

Consent for publication: Informed Consent to Publish-Yes

Availability of data and material: The datasets used and/or analysed during the current study available from the corresponding author on reasonable request.

Competing interests: There is no competing interest.

Funding: It is an INVESTIGATOR INITIATED study, sponsored by Renal Care IIR from Baxter, China (NCT03864120)

\section{Authors' contributions}




\begin{tabular}{|ll|}
\hline Zanzhe Yu & Made a substantial contribution to the concept and design of the work \\
\hline Zhuqing Wang & analysis the data, \\
\hline Qin Wang & Acquisition and interpretation of data \\
\hline Hajiao Jin & Acquisition and interpretation of data \\
\hline Li Ding & Approved the version to be published \\
\hline Hao Yan & Approved the version to be published \\
\hline Jiaying Huang & analysis the data \\
\hline Yan Jin & Approved the version to be published \\
\hline Simon J Davies & Acquisition and interpretation of data \\
\hline Wei Fang & Acquisition and interpretation of data \\
\hline Zhaohui Ni & Acquisition and interpretation of data \\
\hline
\end{tabular}

Acknowledgements: I am grateful to Ms Fenglun Chen and Mr Yuntao Wang for their technical support and Dr Qiang Yao for her general support for the study.

\section{References}

1. Dombros N, Dratwa M, Feriani M, Gokal R, Heimburger O, Krediet R, Plum J, Rodrigues A, Selgas R, Struijk D, Verger $C$ and Dialysis EEGoP. European best practice guidelines for peritoneal dialysis. 7 Adequacy of peritoneal dialysis. Nephrol Dial Transplant. 2005;20 Suppl 9:ix24-ix27.

2. Woodrow $G$ and Davies S. Renal Association Clinical Practice Guideline on peritoneal dialysis. Nephron Clin Pract. 2011;118 Suppl 1:c287-310.

3. Woodrow G, Fan SL, Reid C, Denning J and Pyrah AN. Renal Association Clinical Practice Guideline on peritoneal dialysis in adults and children. BMC Nephrol. 2017;18:333.

4. La Milia V, Pozzoni P, Crepaldi M and Locatelli F. Overfill of peritoneal dialysis bags as a cause of underestimation of ultrafiltration failure. Perit Dial Int. 2006;26:503-5.

5. Davies SJ. Overfill or ultrafiltration? We need to be clear. Perit Dial Int. 2006;26:449-51.

6. Mahon A and Fan SL. Accuracy of ultrafiltration volume measurements for patients on peritoneal dialysis. Perit Dial Int. 2005;25:92-3.

7. Rodriguez-Carmona A and Fontan M. Sodium removal in patients undergoing CAPD and automated peritoneal dialysis. Perit Dial Int. 2002;22:705-713.

8. Rodríguez-Carmona A, Pérez-Fontán M, García-Naveiro R, Villaverde P and Peteiro J. Compared time profiles of ultrafiltration, sodium removal, and renal function in incident CAPD and automated 
peritoneal dialysis patients. American journal of kidney diseases: the official journal of the National Kidney Foundation. 2004;44:132-145.

9. Ortega O, Gallar P, Carreno A, Gutierrez M, Rodriguez I, Oliet A, Vigil A and Gimenez E. Peritoneal sodium mass removal in continuous ambulatory peritoneal dialysis and automated peritoneal dialysis: influence on blood pressure control. Am J Nephrol. 2001;21:189-93.

10. Maharjan SRS and Davenport A. Comparison of sodium removal in peritoneal dialysis patients treated by continuous ambulatory and automated peritoneal dialysis. J Nephrol. 2019;32:10111019.

11. Boudville N andde Moraes TP. 2005 Guidelines on targets for solute and fluid removal in adults being treated with chronic peritoneal dialysis: 2019 Update of the literature and revision of recommendations. Perit Dial Int. 2020;40:254-260.

12. Zhou J, Cao X, Lin H, Ni Z, He Y, Chen M, Zheng H and Chen X. Safety and effectiveness evaluation of a domestic peritoneal dialysis fluid packed in non-PVC bags: study protocol for a randomized controlled trial. Trials. 2015;16:592.

\section{Figures}



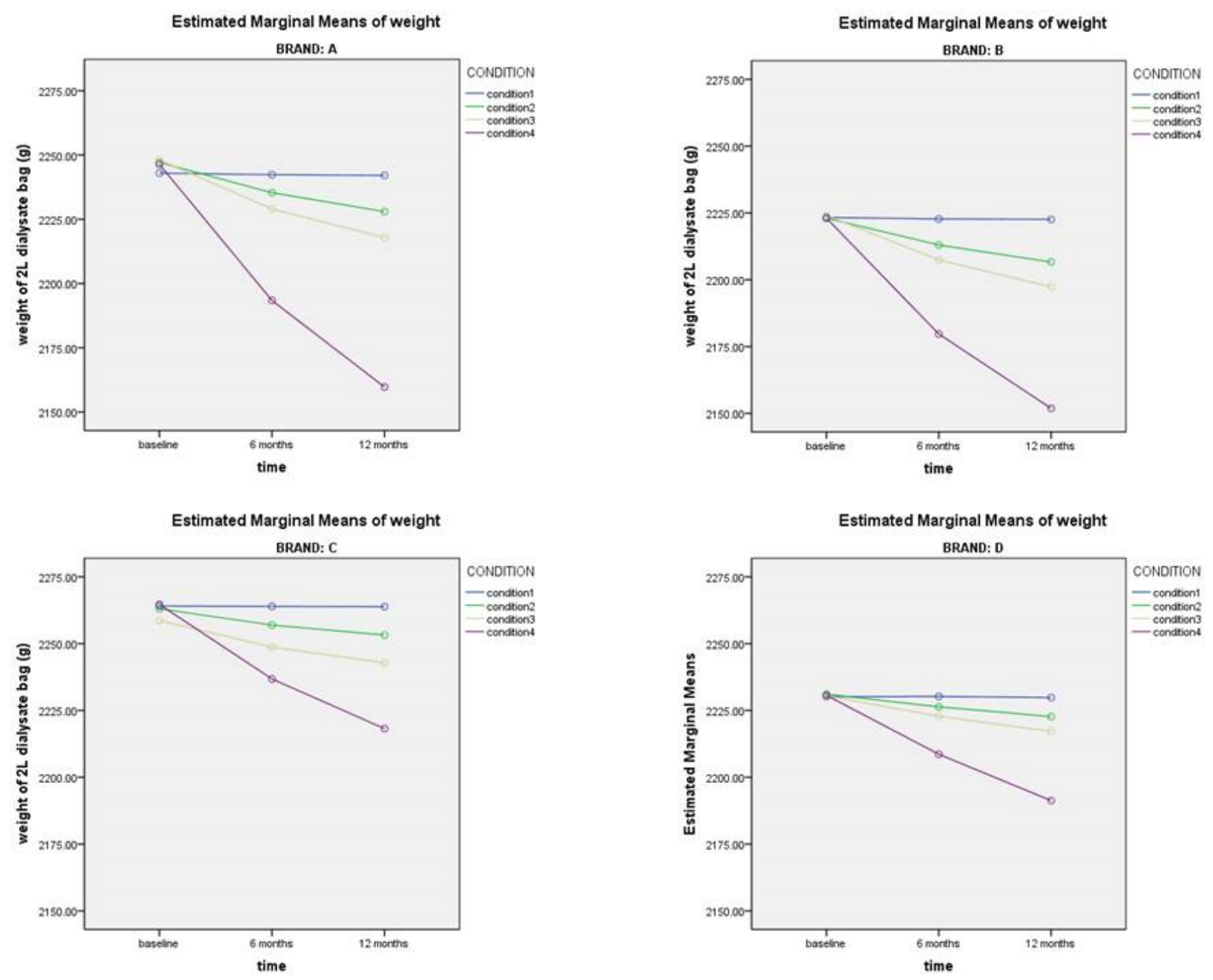

Figure 1

Over the 12 months storage, dialysate lost significant weight. The weight loss was more significant in higher temperature and lower humidity. PVC package was related to more significant weight loss over 12 month's storage.

\section{Supplementary Files}

This is a list of supplementary files associated with this preprint. Click to download.

- appendix.docx 